\title{
Comparativo de capacidade de carga de estacas escavadas por método racional e semiempírico
}

Os métodos para estimativa de capacidade de carga de estacas se constituem, atualmente, em importante e usual ferramenta para projeto, controle e garantia de qualidade de fundações profundas constituídas por estacas escavadas. Apresenta-se no trabalho, resumidamente, soluções de cálculo para obtenção da resistência do solo com a aplicação de uma fundação tipo estaca em uma residência, ou seja, da carga que provoca ruptura do solo sob esse tipo de fundação. Será dada ênfase às contribuições pioneiras no assunto, bem como à comparação dos valores obtidos por métodos racionais que utilizam soluções teóricas para resistência e parâmetros do solo e métodos semiempíricos, que se baseiam em ensaios in situ de penetração.

Palavras-chave: Capacidade de Carga; Geotecnia; Fundações.

\section{Comparative of load capacity of excaved piles by rational and semiempiric method}

The methods for estimating pile load capacity are currently an important and usual tool for the design, control and quality assurance of deep foundations consisting of excavated piles. In the paper, we present, briefly, calculation solutions to obtain soil resistance with the application of a pile foundation in a residence, that is, the load that causes soil breakage under this type of foundation. Emphasis will be given to the pioneering contributions in the subject, as well as to the comparison of the values obtained by rational methods that use theoretical solutions for resistance and soil parameters and semiempirical methods, which are based on in situ penetration tests.

Keywords: Cargo Capacity; Geotechnics; Foundations.

Topic: Engenharia Civil

Reviewed anonymously in the process of blind peer.

Gabriel Farias Conceição Junio

Universidade Federal do Pará, Brasil

http://lattes.cnpq.br/8460376780407617

gabrielfarias034@gmail.com

Paulo Victor Gomes da Silva

Universidade Federal do Pará, Brasil

http://lattes.cnpq.br/694892524493886

http://orcid.org/0000-0001-7767-0510

paulo.victor1997@gmail.com
Received: 08/11/2019

Approved: 19/12/2019
Referencing this:

CONCEIÇÃO JUNIOR, G. F.; SILVA, P. V. G.. Comparativo de capacidade de carga de estacas escavadas por método racional e semiempírico. Technology Science, v.2, n.1, p.18-22, 2020. DOI: http://doi.org/10.6008/CBPC2674-6425.2020.001.0003 


\section{INTRODUÇÃO}

Fundações são elementos estruturais cuja função é transmitir as cargas da estrutura para o terreno onde ela se apoia. Assim as fundações devem ter resistência adequada para suportar as tensões causadas pelos esforços solicitantes. Existem vários tipos de fundações e a escolha do tipo mais adequado é função das cargas da edificação e da profundidade da camada resistente do solo. Com base na combinação destas duas análises optar-se-á pelo tipo que tiver o menor custo e o menor prazo de execução, analisando-se juntamente os mais variados elementos para o desenvolvimento como presença de ruídos, vibrações, tipos de solos, profundidade, cargas, etc..

Um bom projeto deve garantir que as fundações sejam seguras contra dois tipos de estados limites: estados limites últimos, que nas fundações são caracterizados usualmente por ruptura ou deformação plástica excessiva dos materiais ou interfaces, e estados limites de serviço, conhecidos por deslocamentos excessivos (incluindo tanto os deslocamentos permanentes quanto as vibrações de frequência e amplitude incompatíveis com a utilização da edificação para os fins previstos). Uma fundação malfeita representa o insucesso do empreendimento e os problemas podem acontecer tanto no começo da obra, com um desbarrancamento do subsolo, por exemplo, como na entrega da obra, quando o prédio começa a recalcar, por isso deve-se estudar as características do solo onde construção ficará através de sondagens e se escolher o melhor tipo de fundação levando em conta fatores como economia, praticidade, características da vizinhança dentre outros, de modo que seja garantido ao empreendimento o máximo de segurança e conforto ao longo da vida útil do mesmo.

\section{METODOLOGIA}

Para a análise dos métodos de cálculo, foi utilizada uma estaca fictícia com oito metros de comprimento e 20 centímetros de diâmetro, que será de concreto armado e com seu processo construtivo sendo do tipo escavada. Aliado a isso, no experimento em questão foi adotado um furo de sondagem hipotético, que apresentou no laudo 2 metros e 10 centímetros de aterro seguidos de 5 metros e 60 centímetros de argila arenosa com SPT médio de 21.

\section{Cálculo pelo método semiempírico (Aoki-Velloso)}

O método de AOKI e VELLOSO (1975) foi desenvolvido a partir de um estudo comparativo entre resultados de provas de carga em estacas SPT. O método pode ser utilizado tanto com dados SPT como do ensaio CPT. 


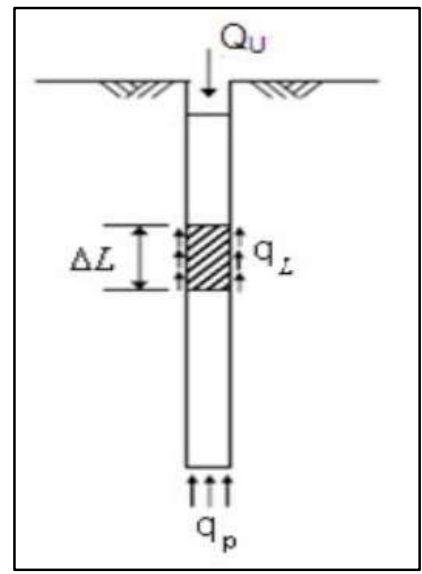

Figura 1: Distribuição de resistência ao longo da estaca.

Foi descartada a resistência lateral do aterro e adotados novos valores de k, $\alpha$, F1 e F2 segundo a contribuição de Laprovitera. O bloco de coroamento da estaca não foi dimensionado, entretanto sua influência nos cálculos não fará diferença, visto que a resistência lateral nos dois primeiros metros foi desconsiderada, uma vez que o material nesse intervalo é aterro.

Tabela 1: Aplicação para o tipo de Estaca.

\begin{tabular}{|l|l|l|}
\hline TIPO DE ESTACA & F1 & F2 \\
\hline Franki & 2,5 & 5,0 \\
\hline Metálica & 1,75 & 3,5 \\
\hline Escavada & 1,75 & 3,5 \\
\hline Pré-Fabricada & 1,75 & 3,5
\end{tabular}

Fonte: Aoki et al. (1975).

Tabela 2: Coeficiente $\alpha$ e k.

\begin{tabular}{|l|l|l|}
\hline \multicolumn{1}{|c|}{ Tipo de Solo } & \multicolumn{1}{c|}{$\boldsymbol{\alpha ( \% )}$} \\
\hline Areia & 1,00 & 1,4 \\
\hline Areia Siltosa & 0,80 & 2,0 \\
\hline Areia Silto - Argilosa & 0,70 & 2,4 \\
\hline Areia Argilosa & 0,60 & 3,0 \\
\hline Areia Argilo - Siltosa & 0,50 & 2,8 \\
\hline Silte & 0,40 & 3,0 \\
\hline Silte Arenoso & 0,55 & 2,2 \\
\hline Silte Areno - Argiloso & 0,45 & 2,8 \\
\hline Silte Argiloso & 0,23 & 3,4 \\
\hline Silte Argilo - Arenoso & 0,25 & 3,0 \\
\hline Argila & 0,20 & 6,0 \\
\hline Argila Arenosa & 0,35 & 2,4 \\
\hline Argila Areno - Siltosa & 0,30 & 2,8 \\
\hline Argila Siltosa & 0,22 & 4,0 \\
\hline Argilo Silto - Arenosa & 0,33 & 3,0
\end{tabular}

Fonte: Aoki et al. (1975).

$$
\begin{gathered}
P l=r l * A l(1) \\
r l=\alpha * k * N * F 2^{-1}(2) \\
A l=\operatorname{Per} * \Delta L(3)
\end{gathered}
$$

As fórmulas acima são utilizadas no cálculo da resistência lateral por atrito $\mathrm{PL}$, onde $\mathrm{rl}, \mathrm{Al}$ e $\mathrm{Per}$ são respectivamente a resistência unitária lateral, área lateral da estaca, perímetro da estaca. $\Delta \mathrm{L}$ é a espessura da camada, $\alpha$ e k são os coeficientes conforme o tipo de solo. As variáveis N e F2 são nessa ordem, a média dos valores de NSPT ao longo da camada e o coeficiente conforme o tipo de estaca. No cálculo foi considerado 
uma estaca escavada de concreto armado com $8 \mathrm{~m}$ de comprimento, base com 0,2m de diâmetro, valores de $\alpha$ e k obtidos da tabela 2 e espessura da camada de argila arenosa de 5,6m com NSPT médio de 21.

$$
\begin{aligned}
P p & =r p * A p(4) \\
r p & =k * N p * F 1^{-1}(5)
\end{aligned}
$$

São utilizadas no cálculo da resistência de ponta, onde rp, Ap, k são respectivamente a resistência unitária de ponta, área de ponta da estaca, coeficiente conforme o tipo de solo (tabela 2). Np representa os valores de NSPT da camada de apoio e F1 o coeficiente conforme o tipo de estaca.

\section{Cálculo pelo método racional (Terzaghi)}

O método de Terzaghi será para resistência de ponta e o método da abordagem geral para solos granulares para resistência lateral.

\begin{tabular}{|c|c|c|c|c|c|c|}
\hline$\varphi$ & Nc & $\mathrm{Nq}$ & $\mathbf{N} \gamma$ & $N^{\prime} c$ & $N^{\prime} q$ & $\mathbf{N}^{\prime} \gamma$ \\
\hline 0 & 5,7 & 1,0 & 0,0 & 5,7 & 1,0 & 0,0 \\
\hline 5 & 7,3 & 1,6 & 0,5 & 6,7 & 1,4 & 0,2 \\
\hline 10 & 9,6 & 2,7 & 1,2 & 8,0 & 1,9 & 0,5 \\
\hline 15 & 12,9 & 4,4 & 2,5 & 9,7 & 2,7 & 0,9 \\
\hline 20 & 17,7 & 7,4 & 5,0 & 11,8 & 3,9 & 1,7 \\
\hline 25 & 25,1 & 12,7 & 9,7 & 14,8 & 5,6 & 3,2 \\
\hline 30 & 37,2 & 22,5 & 19,7 & 19,0 & 8,3 & 5,7 \\
\hline 35 & 57,8 & 41,4 & 42,4 & 25,2 & 12,6 & 10,1 \\
\hline 40 & 95,7 & 81,3 & 100,4 & 34,9 & 20,5 & 18,8 \\
\hline 45 & 172,3 & 173,3 & 297,5 & 51,2 & 35,1 & 37,7 \\
\hline
\end{tabular}

Tabela 3: Fatores de Capacidade de Carga.

Fonte: Bowles (1996).

$$
Q p, u l t=1,2 * c * N c+\gamma * L * N q+0,6 * \gamma * 0,5 * B * N \gamma(6)
$$

Equação para a resistência de ponta, onde Qp, ult, c e y são respectivamente a tensão efetiva ao nível da base, coesão do solo e peso específico do solo. B é a dimensão da estaca e L seu comprimento. Os fatores $\mathrm{Nc}, \mathrm{Nq}$ e Ny representam os fatores de capacidade de carga (BOWLES, 1996).

\section{RESULTADOS E DISCUSSÃO}

É válido ressaltar que na prática, o projeto estrutural é feito de acordo com os ensinamentos da Estática das Construções da Resistência dos Materiais e da perfeita avaliação dos esforços externos que solicitam as estruturas. Dito isso, modelos teóricos e semiempíricos não sinalizam totalmente o que ocorre no solo, visto que são métodos aproximados de capacidade de carga. Com a obtenção dos resultados é notória a discrepância entre os resultados, sinalizando a incerteza existente nos métodos de cálculo.

Tabela 4: Resultado dos cálculos por cada método.

\begin{tabular}{|l|l|l|}
\hline MÉTODO & AOKI, VELOSO & \multicolumn{2}{c|}{ TERZAGHI } \\
\hline Resistência Lateral (KN) & 309,17 & 374,81 \\
\hline Resistência de Ponto (KN) & 134,73 & 123,27 \\
\hline Resistência Total (KN) & $44,3,9$ & 498,08 \\
\hline
\end{tabular}




\section{CONCLUSÕES}

O referente trabalho simulou os desafios em conciliar a teoria versus a prática, uma vez que houve a necessidade de uma análise criteriosa para melhor tomada de decisão, desde dos métodos construtivo até para os cálculos de capacidade de carga e recalque, haja vista que o solo é um material não homogêneo e suas propriedades se alteram de acordo com inúmeras variáveis.

Dessa maneira, o conhecimento teórico e experiência profissional são fundamentais para a definição dos parâmetros que serão utilizados para os cálculos e os fatores de influência que serão considerados. Assim, essas informações serão decisivas para os critérios de escolha do tipo de fundação que seja propicia ao referente solo.

Diante disso, há necessidade de estudos geotécnicos nos solos que suportarão as estruturas definidas pelos projetos, através de sondagens do tipo SPT ou CPT para aferir os parâmetros das camadas que constitui o solo. Por meio disso, pode-se utilizar métodos teóricos e semiempíricos para determinação da capacidade de carga do solo, determinação das dimensões da fundação e os referentes recalques que irão ocorrer devido as cargas que atuarão na estrutura.

\section{REFERÊNCIAS}

AOKI, N.; VELLOSO, D. A.. An approximate method to estimate the bearing capacity of piles. In: PAN-AMERICAN CONF. OF SOIL MECHANICS AND FOUNDATION ENGINEERING, 5. Anais. Buenos Aires: International Society of Soil Mechanics and Geotechnical Engineering, 1975 p.367-376.

BOWLES, L. E.. Foundation analysis and design. McGraw-hill, 1996.

A CBPC - Companhia Brasileira de Produção Científica (CNPJ: 11.221.422/0001-03) detém os direitos materiais desta publicação. Os direitos referem-se à publicação do trabalho em qualquer parte do mundo, incluindo os direitos às renovações, expansões e disseminações da contribuição, bem como outros direitos subsidiários. Todos os trabalhos publicados eletronicamente poderão posteriormente ser publicados em coletâneas impressas sob coordenação da Sapientiae Publishing, da Companhia Brasileira de Produção Científica e seus parceiros autorizados. Os (as) autores (as) preservam os direitos autorais, mas não têm permissão para a publicação da contribuição em outro meio, impresso ou digital, em português ou em tradução. 